\title{
Approaching the Truth of the Missing Carbon Sink
}

\author{
Wenfeng Wang ${ }^{1}$, Xi Chen ${ }^{1 *}$, Lunche Wang ${ }^{2}$, Heng Zhang ${ }^{3}$, \\ Gang Yin', Yifan Zhang ${ }^{4}$
}

${ }^{1}$ State Key Laboratory of Desert and Oasis Ecology, Xinjiang Institute of Ecology and Geography, Chinese Academy of Sciences, Urumqi, 830011, China

${ }^{2}$ School of Earth Science, China University of Geosciences, Wuhan, 430074, China

${ }^{3}$ Department of Mathematics and Computer Science, Fujian Normal University, Fuqing, 350300, China

${ }^{4}$ Department of Chemistry, Inha University, 100 Inharo, Incheon 402-751, South Korea

Received: 27 January 2016

Accepted: 23 March 2016

\begin{abstract}
Numerous efforts in investigating the global carbon balance have concluded that the global $\mathrm{CO}_{2}$ budget cannot be balanced unless a "missing carbon sink" is invoked. Until now there have been considerable uncertainties as to the magnitude of the C-sink in different regions and the contributions of aboveground/ underground processes. This study is aimed at presenting a first estimate of the gap between observed soil respiration and its biological components in arid areas that characterize more than $30 \%$ of Earth's total land surface. In the current literature, soil respiration flux is interpreted in the context of an unstated hypothesis that the fluxes were largely determined by underground biological processes. However, the assumption turned out to be incorrect. Negative soil respiration fluxes in unneglectable arid regions implied a gap in our knowledge. The first estimate of the gap between observed soil respiration flux and its biological components in the global arid regions is a beginning at determining the size of the missing $\mathrm{C}$-sink.
\end{abstract}

Keywords: carbon cycle, arid region, soil respiration

\section{Introduction}

Atmospheric $\mathrm{CO}_{2}$ levels $\left(\left[\mathrm{CO}_{2}\right]\right)$ have increased $30 \%$ in the past century [1]. Motivated by such a rapid increase of $\left[\mathrm{CO}_{2}\right]$ and the climate changes it produced, numerous studies have been carried out to account for the global atmospheric $\mathrm{CO}_{2}$ fluxes by quantifying $\mathrm{C}$ sources and sinks. However, the results reveal that the global $\mathrm{CO}_{2}$

*e-mail: chenxi@ms.xjb.ac.cn budget cannot be balanced, unless a 'missing carbon sink' is invoked [2]. Numerous research has been carried out to locate this sink. Isotopic studies revealed that air-sea $\mathrm{CO}_{2}$ exchange is too small to explain it [3]. So it should be accounted for by terrestrial ecosystems, which brought more uncertainty. Carbon accumulation in a forest was found to be counter-balanced by carbon loss during deforestation, but the size and mechanism of this sink is far from certain [4]. A sink was found in the root system, but finally turned out to be insignificant $[5,6]$. Although the role of river and groundwater in $\mathrm{CO}_{2}$ transport, the role 
of soil erosion on carbon consumption, and the role of soils management in increasing soil carbon storage have been studied $[7,8]$, whether soil is a source or sink is still a subject of debate [9].

It is therefore imperative to establish an improved understanding of the processes involved in the $\mathrm{C}$ balance at the ecosystem scale. In most literature, micrometeorological measurements of the net ecosystem exchange (NEE) of $\mathrm{CO}_{2}$ around the global flux towers interpret NEE as biological fluxes, and specifically defines them as a sum of photosynthetic and respiratory components [10]. However, some recent publications highlighted the necessity to include the abiotic flux components of soil respiration in NEE [11]. Until now, the mechanisms of abiotic flux components and their overall importance to overall ecosystem $\mathrm{CO}_{2}$ balance are still a subject of debate [12]. This is a dilemma: estimates of the importance deserve a huge effort of the worldwide scientific communities, but such wide attention and huge effort are impossible because the mechanisms have finally been determined.

Our major objective in this study is to present a first estimate of the gap between observed soil respiration and its biological components in arid areas that characterize more than $30 \%$ of the Earth's total land surface. Additionally, some unresolved issues are highlighted for future investigation to work out more exact estimates of the gap.

\section{Materials and Methods}

Analyses in this study were based on some theoretical $\mathrm{C}$ balance equations and the output data of an incorporated model for soil respiration flux for arid ecosystems [1]. Recall that the derivative of the exponential chemical reaction-temperature equation has been developed as an incorporative $\mathrm{Q}_{10}$ model [13]:

$$
\left\{\begin{array}{c}
F_{\mathrm{c}}=F_{a}+F_{x} \\
F_{a}=R_{10} Q_{10}{ }^{(T-10) / 10} \\
F_{x}=r_{7} q_{7}{ }^{p H-7}+\lambda T+\mu \theta_{S}+e
\end{array} .\right.
$$

... where $F_{c}$ is overall soil respiration flux, $F_{a}$ is soil abiotic respiration flux, $F_{x}$ is soil biotic respiration flux, $T_{a}$ is surface air temperature, $\mathrm{pH}$ is soil alkalinity, and $\theta_{\mathrm{s}}$ is soil volumetric water content at $5 \mathrm{~cm}$ depth in the soil, and the fitted parameters are $\lambda=0.0059, \mu=0.0003, r_{7}=3.0191$, $\mathrm{q}_{7}=0.7562, \mathrm{e}=-2.5081, \mathrm{R}_{10}=0.3625$, and $\mathrm{Q}_{10}=1.5$.

This incorporative model divides the database of $F_{c}$ into a sum of the dataset of soil biotic respiration flux $\left(\mathrm{F}_{\mathrm{a}}\right)$ and the dataset of soil abiotic respiration flux $\left(\mathrm{F}_{\mathrm{x}}\right)$. And these two sub-datasets have been further reconciled as another two sub-datasets: the sub-dataset of soil $\mathrm{CO}_{2}$ effluxes $\left(\mathrm{F}_{\mathrm{e}}\right)$ and the sub-dataset of soil $\mathrm{CO}_{2}$ influxes $\left(\mathrm{F}_{\mathrm{i}}\right)$ :

$$
\begin{gathered}
F_{x+}=\left(F_{x}+\left|F_{x}\right|\right) / 2 \quad F_{x-}=\left(F_{x}-\left|F_{x}\right|\right) / 2 \\
F_{e}=F_{a}+F_{x+} \quad F_{i}=F_{x-} .
\end{gathered}
$$

... where $\mathrm{F}_{\mathrm{x}+}$ and $\mathrm{F}_{\mathrm{x}-}$ are two half components of $\mathrm{F}_{\mathrm{x}}$ (termed as the efflux and influx in $\mathrm{F}_{\mathrm{x}}$, respectively, according to the efflux and influx definitions in [14].

In the present study, the gap between observed soil respiration flux and its biological components in the arid regions is defined as the overall importance of $F_{x}$. Both the model (1) and the estimates in [1] are hypothetically have global implications.

\section{Results and Discussions}

Central Asian is a large, typical arid region in the global land surface area. It occupies almost half of the total arid Eurasian hinterland and the area is about $34 \%$ of global arid regions (Fig. 1). If the current measurements [1, 13] represent an average for the Eurasian hinterland, then the first approach of the regional gap amounts to $1.26 \mathrm{Pg} \mathrm{C}$, approaching $70 \%$ of missing global C-sink; if the current measurements have global implications and represent an average for saline-alkali soils of earth's arid areas, then the global gap amounts to $1.85 \mathrm{Pg} \mathrm{C}$, approaching the missing global sink. Consequently, neglecting $\mathrm{F}_{\mathrm{x}}$ leads to ecosystem respiration, which is surely overestimated in arid regions and may be responsible for the missing sink.

This implies that we must reconcile the balance equation for the dynamics of atmospheric level $\left(\mathrm{CO}_{2}\right)$, which has been widely recognized in previous publications as

$$
\mathrm{dCO}_{2} / \mathrm{dt}=\mathrm{C}+\mathrm{D}+\mathrm{R}+\mathrm{O}-\mathrm{P}-\mathrm{I}-\mathrm{S}
$$

...where $\mathrm{C}$ and $\mathrm{D}$ are $\mathrm{CO}_{2}$ releases from the fossil fuel combustion and land use change, respectively; $\mathrm{P}$ is photosynthetic $\mathrm{CO}_{2}$ absorption; $\mathrm{O}$ and I are oceanic $\mathrm{CO}_{2}$ release and absorption, respectively; $\mathrm{S}$ is the organic/ inorganic carbon sequestration in the ocean and terrestrial ecosystems; and $\mathrm{R}=\mathrm{R}_{\mathrm{a}}+\mathrm{R}_{\mathrm{r}}$ is ecosystem respiration, a direct sum of autotrophic and heterotrophic respiration [15-20].

The readings from Xinjiang and Central Asia [1] can be influential. In the current literature, soil respiration flux $\left(\mathrm{F}_{\mathrm{c}}\right)$ is interpreted in the context of an unstated hypothesis that biological processes largely determine $F_{c}$ [21]. However, the assumption turned out to be incorrect in arid and semi-arid systems [9-13, 22]. Considering the gap between observed soil respiration flux and its biological components in the arid regions (i.e., taking into account of the overall importance of $F_{x}$ ), the budget of $R$ in Eq. (4) should be revised to $R=R_{a}+R_{r}+F_{x}$. 


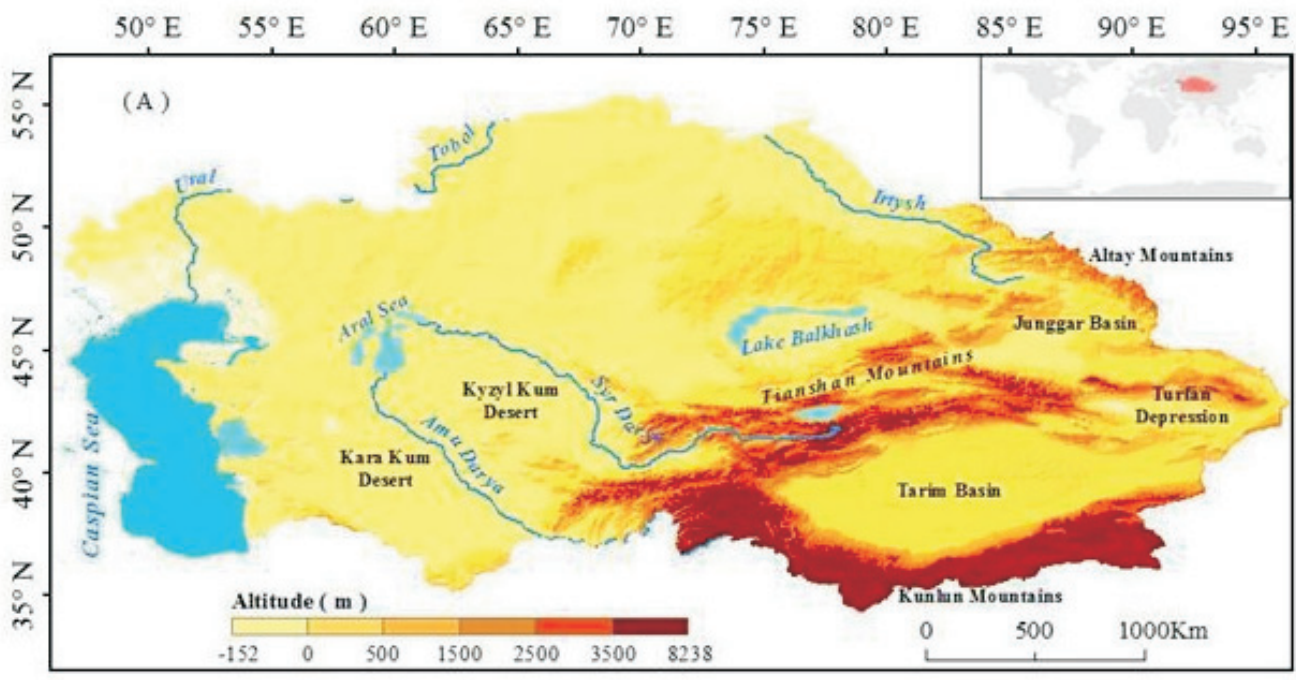

Fig. 1. The role of Central Asia in global arid regions.

Decades of measuring atmospheric $\left(\mathrm{CO}_{2}\right)$ inventory lists and detailed surface carbon-flux measurements around the world has revealed that there is more $\mathrm{CO}_{2}$ being released into the atmosphere then predicted from the increase in measured $\left(\mathrm{CO}_{2}\right)$ [23]. Although widespread recognition of the significance of carbon dynamics in terrestrial ecosystems has been well researched [21, 23], there remains considerable uncertainties as to the magnitude of the sink in different regions and the contribution of different processes $[5,6]$. Combining with theory and analyses in the previous publications, the gap between the biologically produced $\mathrm{CO}_{2}$ "real soil respiration" (solely interpreted as biological components, autotrophic and heterotrophic respiration) and actual measured $F_{c}[24,25]$ can further highlight a gap in our knowledge.

Nevertheless, the geochemical kinetics of soil abiotic $\mathrm{CO}_{2}$ exchange in arid regions still needs more detailed understanding (Fig. 2). Future efforts should focus on uncertainties and matters of controversy on mechanisms of nonbiological processes [26]. And based

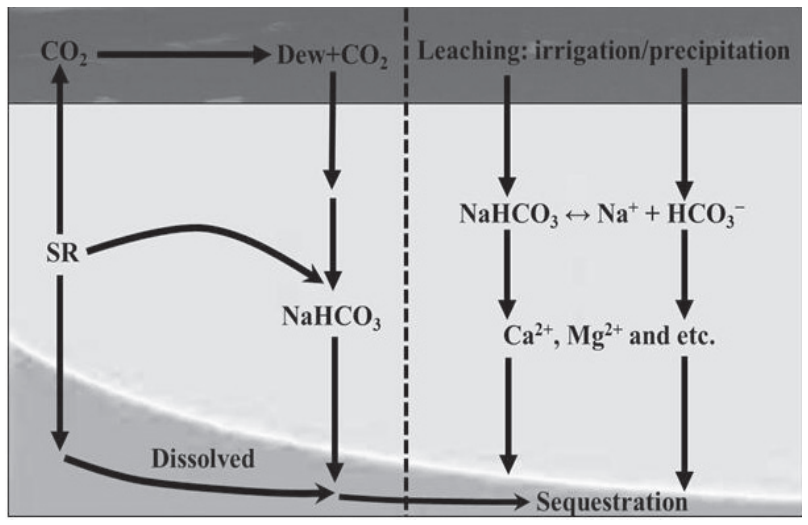

Fig. 2. Geochemical kinetics of soil abiotic $\mathrm{CO}_{2}$ exchange in arid areas. on such efforts, more elaboration of the estimates between observed soil respiration and its biological components can be approached. Therefore, further investigations on the respiration dynamics of these soils are of global importance to refine the components to the world's carbon cycle. To improve our estimates of soil carbon dynamics, unresolved issues for future investigation include: 1) to measure the contribution of biological and non-biological carbon flux in alkaline soils of arid areas, 2) to develop a model of the environmental drivers that determine the release and capture rate of $\mathrm{CO}_{2}$ by these soils, and 3) to model the contributions of these soils to the global carbon budget.

\section{Conclusions}

Although the mechanisms of non-biological processes involved in soil respiration fluxes are still a matter of controversy, the first estimate of the gap between the observed soil respiration fluxes and its biological components in alkaline soils of global arid areas is very promising. This built a new approach to the truth of the mysterious missing carbon sink. It is worth conducting large-scale investigations and refining the statistical approach to the gap. To reduce uncertainties in predictions of future feedback in the coupled carbon-climate system and in the current global/regional carbon balance, further improvement of our knowledge on carbon exchange between the atmosphere and alkaline land is also essentially necessary.

\section{Acknowledgements}

This work was financially supported by the National Natural Science Foundation of China (41571299), the CAS "Light of West China" Program (XBBS2014-16), the Shenzhen ICSTI Basic Research Project 
(JCYJ20150630114942260) and the "Thousand Talents" plan (Z474161). Essential geodata were collected from National Science \& Technology Infrastructure CenterData Sharing Infrastructure of Earth System Science .

\section{References}

1. CHEN X., WANG W.F., LUO G.P., et al. Can soil respiration estimate neglect the contribution of abiotic exchange? Journal of Arid Land, 6 (2), 129, 2014.

2. INGLIMA I., ALBERTI G., BERTOLINI T., et al. Precipitation pulses enhance respiration of Mediterranean ecosystems: the balance between organic and inorganic components of increased soil $\mathrm{CO}_{2}$ efflux. Global Change Biology, 15, 1289, 2009.

3. KOWALSKI A.S., SERRANO-ORTIZ P., JANSSENS I.A., et al. Can flux tower research neglect geochemical $\mathrm{CO}_{2}$ exchange? Agricultural and Forest Meteorology, 148, 1045, 2008.

4. MA J., WANG Z.Y., STEVENSON B.A., et al. An inorganic $\mathrm{CO}_{2}$ diffusion and dissolution process explains negative $\mathrm{CO}_{2}$ fluxes in saline/alkaline soils. Scientific reports, 3, 2025, 2013. PubMed: 23778238.

5. SCHIMEL D.S., BRASWELL B.H., HOLLAND E.A., et al., Climatic, edaphic, and biotic controls over storage and turnover of carbon in soils. Global Biogeochemical Cycles, 8, 279, 1994.

6. SCHIMEL D.S., HOUSE J.I., HIBBARD K.A., et al. Recent patterns and mechanisms of carbon exchange by terrestrial ecosystems. Nature, 414, 169, 2001.

7. TANS P.P., FUNG I.Y., TAKAHASHI T. Observational constraints on the global atmospheric $\mathrm{CO}^{2}$ budget. Science, 247, 1431, 1990.

8. WOFSY S.C. Where has all the carbon gone? Science, 292, 2261, 2001

9. XIE J.X., LI Y., ZHAI C.X., et al. $\mathrm{CO}_{2}$ absorption by alkaline soils and its implication to the global carbon cycle. Environmental Geology, 56, 953, 2009.

10. SERRANO-ORTIZ P., ROLAND M., SÁNCHEZ-MORAL S., et al. Hidden, abiotic $\mathrm{CO}_{2}$ flows and gaseous reservoirs in the terrestrial carbon cycle: review and perspectives. Agricultural and Forest Meteorology, 150, 321, 2010.

11. WOHLFAHRT G., FENSTERMAKER L.F., ARNONE J.A. Large annual net ecosystem $\mathrm{CO}_{2}$ uptake of a Mojave Desert ecosystem. Global Change Biology, 14, 1475, 2008.

12. STONE R. Have desert researchers discovered a hidden loop in the carbon cycle? Science, 320, 1409, 2008.

13. WANG W.F., CHEN X., LUO G.P., et al. Modeling the contribution of abiotic exchange to $\mathrm{CO} 2$ flux in alkaline soils of arid areas[J]. Journal of Arid Land, 6 (1), 27, 2014.

14. CHEN X., WANG W.F., LUO G.P., et al. Time lag between carbon dioxide influx to and efflux from bare saline-alkali soil detected by the explicit partitioning and reconciling of soil $\mathrm{CO}_{2}$, flux [J]. Stochastic Environmental Research \& Risk Assessment, 27 (3), 737, 2013.

15. ZHANG Q.B., YANG L., XU Z.Z., et al. Effects of cotton field management practices on soil $\mathrm{CO}_{2}$ emission and $\mathrm{C}$ balance in an arid region of Northwest China[J]. Journal of Arid Land, 6 (4), 468, 2014.

16. CHANG Z.Q., LIU X.Q., FENG Q., et al. Non-growing season soil $\mathrm{CO}_{2}$, efflux and its changes in an alpine meadow ecosystem of the Qilian Mountains, Northwest China[J]. Journal of Arid Land, 5 (4), 488, 2013.

17. YAN J.X., LI H.J., YOU L.F. Studies on soil respiration and its relation with environmental factors in a Maize (Zea mays L.) field in Taiyuan Basin[J]. Journal of Arid Land Resources \& Environment, 24 (3), 183, 2010.

18. FAN Y., LI P.F., HOU Z.A., et al. Water adaptive traits of deep-rooted C halophyte (Karelinia caspica (Pall.) Less.) and shallow-rooted C4 halophyte (Atriplex tatarica L.) in an arid region, Northwest China[J]. Journal of Arid Land, 4 (4), 469, 2012.

19. LI C.J., ZENG F.J., ZHANG B., et al. Optimal root system strategies for desert phreatophytic seedlings in the search for groundwater[J]. Journal of Arid Land, 7 (4), 462, 2015.

20. LUO Y.Q., ZHAO X.Y., ANDREN O., et al. Artificial root exudates and soil organic carbon mineralization in a degraded sandy grassland in northern China[J]. Journal of Arid Land, 6 (4), 423, 2014.

21. WANG X.H., PIAO S.L., CIAIS P., et al. Are ecological gradients in seasonal $\mathrm{Q}_{10}$ of soil respiration explained by climate or by vegetation seasonality? Soil Biology \& Biochemistry, 42, 1728, 2010.

22. WANG Y., WANG Z., LI Y. Storage/turnover rate of inorganic carbon and its dissolvable part in the profile of saline/alkaline soils. PloS one, 8 (11), e82029, 2013.

23. SCHINDLER D.W. The mysterious missing sink. Nature, 398,105, 1999.

24. REY A. Mind the gap: non-biological processes contributing to soil $\mathrm{CO}_{2}$ efflux. Global change biology, doi: http://dx.doi. org/ 10.1111/gcb.12821, 2014.

25. SANCHEZ-CAÑETE E.P., SERRANO-ORTIZ P., KOWALSKI A.S., et al. Subterranean $\mathrm{CO}_{2}$ ventilation and its role in the net ecosystem carbon balance of a karstic shrubland. Geophysical Research Letters, 38, L09802, 2011.

26. SCHLESINGER W.H., BELNAP J., MARION G. On carbon sequestration in desert ecosystems. Global Change Biology, 15, 1488, 2009. 